\title{
A technology map to facilitate the process of mine modernization throughout the mining cycle
}

\author{
by J. Jacobs* and R.C.W. Webber-Youngman*
}

\section{Synopsis}

It is vital for organizations and individual operations to have access to a platform with technology-related information to consider for further research and development. This paper presents a technology map that was created with the purpose of facilitating mine modernization through technological advancement throughout the mining lifecycle/cycle.

To achieve this, a platform was created to represent the mining lifecycle that incorporates each of the mining phases, i.e. exploration, project evaluation, mine design, operations, closure, and post-closure phases. The constituent value drivers for each phase were then investigated and included. These covered the various focus areas within the mining cycle, such as the applicable sub-phases, processes, systems, activities, or specific challenges, that impact a mine's operation.

Technologies, both physical and digital, with the potential to add value to these focus areas were then incorporated into the platform to create a technology map. This potential to add value, if applied or modified for application, was assessed on any combination of five factors, namely the ability to increase production, increase productivity, increase efficiency, improve safety, or reduce the risk of human error. The primary focus was on technologies currently classified as disruptive and/or exponential, e.g. internet of things, cloud computing, advanced robotics, genomics, 3D printing, and artificial Intelligence. Other emerging technologies were also investigated, such as automation, machine learning, renewable energy generation, energy storage, advanced materials, and more. Furthermore, selected innovative technologies adapted for or developed in mining were also investigated, as well as other new technologies in non-mining industries with potential to add value to mining. As such, a technology map was created that covers the entire lifecycle of a mining venture, which highlights technologies with the potential to add value to specific focus areas. This technology map may be applied to facilitate advances in technology for mine modernization.

\section{Keywords}

modernization, new technologies in mining, innovation in mining, technology map, mining cycle, mine life-cycle, mining $R \& D$.

\section{Introduction}

The global mining industry is currently under pressure and is at the bottom of the largest mining supercycle since the Second World War (Bryant, 2011). Mining companies face everincreasing challenges to profitability due to low commodity prices, increasingly tough mining conditions, and rising pressure from stakeholders (Deloite, 2014). In the short term, the decreased commodity prices have been straining cash flows, while in the longer term many existing mines are maturing, thereby resulting in the extraction of lower ore grades and longer haul distances from the excavation face. Orebody replacement rates are also declining and the duration of development for new mines is increasing. Added to this, worldwide mining operations are up to $28 \%$ less productive today than they were a decade ago, and that is after adjusting for declining ore grades (McKinsey, 2015a).

Depleting ore reserves and declining ore grades in existing operations also means that companies are required to mine deeper to reach new deposits, which in turn increases costs and results in reduced profits. Since the start of the 21 st century, over $75 \%$ of new base metal discoveries have been at depths greater than $300 \mathrm{~m}$ (Deloite, 2014), highlighting both the gradual depletion of shallower reserves and the need for deeper mining. However, mining at these depths involves additional challenges, such as safety issues, flooding, gas discharges, seismic events, and ventilation problems (Deloite, 2014).

Apart from the fact that mining operations are now deeper, the geology is also more challenging and mines operate at higher risk. The result is that continuous business improvement alone is no longer sufficient for companies to survive (Deloitte, 2016). At the 2015 Johannesburg Mining Indaba in South Africa, Chris Griffith (CEO of Anglo American Platinum) stated:

Given the magnitude of our extraction challenges, it is quite extraordinary that the global mining industry currently spends so little on innovation and business-improvement programmes. On a revenue-to-revenue basis, the industry spends $80 \%$ less on technology and innovation compared with the petroleum sector, for example. Yet our operating costs are increasing three times faster than consumer-inflation rates and are

* University of Pretoria, South Africa.

(c) The Southern African Institute of Mining and Metallurgy, 2017. ISSN 2225-6253. This paper was first presented at the 3rd Young Professionals Conference, 9-10 March 2017, Innovation Hub, Pretoria, South Africa. 


\section{A technology map to facilitate the process of mine modernization}

on their way to doubling in less than five years. With industry margins being squeezed on all fronts, we simply have to embrace innovation if we want to find more productive, efficient and sustainable ways of extracting value from the minerals we mine. We can't rely on only small, incremental changes and a business-as-usual philosophy to get us out of this predicament. Major innovation is exactly what our industry needs to solve its critical challenges. In fact, mining needs to leap forward 20 years in the next five...'

This statement is in line with the growing consensus that incremental operational improvements are no longer sufficient to sustain the mining sector as a whole. It further explains why many leading organizations are rallying behind the innovation imperative that calls for major transformation to business models and strategies (Deloitte, 2014). This is especially true with the impending technological revolution, where innovation will form a key component in making businesses sustainable. This holds true not only for the mining industry, but for all industries and individual organizations worldwide (ESPAS, 2015).

In this upcoming technological age, the lines distinguishing businesses will become increasing blurred as businesses become more technology-based (Bryant, 2011). Technology will become more integrated into all aspects of business as a tool for human assistance, with the application thereof being business-specific. As such, the silos in which various industries and sectors place themselves may disappear altogether as they experience an increased convergence towards becoming technology businesses first and foremost. In order to then draw from the knowledge and expertise of a growing business cluster, a holistic approach to innovation will be required that takes cognisance of a larger pool of potentially similar organizations.

As a result, it becomes increasingly important to improve the innovation efforts within a business by looking at technology trends across various industries. Many technologies exist (or are in the development phase) that may be applicable or may be modified for use in the mining industry. With the increase in technological advancement worldwide, it is also important for the mining industry to remain aware of cross-sectorial innovations that may have an impact in future. This is especially true when it comes to exponential and disruptive technologies. These are technologies for which the adoption curve, instead of following a linear trend with a steady rise, initially remains flat and then accelerates dramatically. Exponential technologies, such as 3D printing and artificial intelligence, often disappoint in their early years before adoption accelerates. Companies often overlook the value of such technologies in their initial stages, when they should have been exploring them (Deloitte, 2016b).

Operational performance excellence relies on the innovative use of such technologies and keeping abreast with developments that may add value to a given component within the mining value chain (Rivard, 2014), as well as in the broader mining cycle. As such, the focus should be on introducing proven technology from other industries combined with the development of new technologies. In this way the mining industry will progressively focus more on integrating all activities across the value chain. This includes the continued introduction and development of Integrated Remote Operation Centres (IROC), mechanization, and automation (MacFarlane, 2014). Such technological advances and implementations in mining form part of the modernization drive currently taking place in the South African mining industry. The Chamber of Mines of South Africa describes mine modernization as 'a process of transition and transformation of the mining industry of yesteryear and today to that of tomorrow' (COMSA, 2016). In the context of this paper, the term modernization refers to the innovative implementation, adoption, and advancement of technologies in order to create value and allow the transition towards a more technologically advanced and modernized industry.

In order to accomplish the value-added end-goals, such as mechanization, automation, and modernization as a whole, the supporting technologies need to be evaluated in detail. From these and many other technologies, mining operations can also achieve multiple other benefits and 'quick wins' (MacFarlane, 2014). It should be noted that the mining industry is often not aware of emerging technologies that could potentially add value to operations, or which may disrupt aspects of the business. The continuous assessment of technologies, in terms of impact or benefit, can then be considered as a growing business priority in order to gain an understanding of how opportunities could be exploited, or possible detrimental impacts negated or avoided. In doing so, an organization will be working towards enhancing its operational risk management strategies, minimizing negative consequences from external technological factors, and identifying potential improvements to an operation or the organization as a whole.

It is therefore vital that companies and individual operations have access to a platform that can provide technology-related information in the context of the various aspects within the mining cycle. For this reason, a technology map was created. To achieve this, it was first necessary to create a platform that represents the entire mining cycle and the underlying six mining phases, namely exploration, project evaluation, mine design, operations, closure, and post-closure. Each of these was further expanded into the focus areas that contain the value drivers impacting on a mine's operation, such as constituent sub-phases, processes, systems, activities, or specific challenges, with potential to increase or decrease value for the organization. The value drivers were then categorized under seven main value driving pillars, namely mineral resource management; production; productivity and asset efficiency; profitability and cost control; supply chain; socio-economic factors; and health, environment, safety, and legal. These seven pillars were represented throughout the six mining phases to form a seven-by-six matrix.

Numerous technologies, ranging from physical to digital, were then analysed. Analysis was based on any combination of five qualifying factors - the ability to:

> Increase production (as a measure of effectiveness, e.g. tons extracted)

> Increase productivity (as a measure of efficiency, e.g. resources, such as time and money, used to extract a specific amount of tonnages)

> Increase efficiency (as a measure distinct from 


\section{A technology map to facilitate the process of mine modernization}

productivity, e.g. an increase in efficiency that may not have a direct impact on production but still adds value to the organization, such as a more efficieny payroll system)

> Improve safety (as a measure of reducing the likelihood and severity of potential causes of harm to people)

$>$ Reduce the risk of human error (a measure of decreasing the likelihood of blunders or mishaps).

Accordingly, those technologies with potential to add value, and as such facilitate the process of mine modernization, were slotted into the applicable focus areas within the mining cycle. A technology map was thus created spanning the entire mining cycle, which highlights technologies with the potential to add value. These technologies may then be subjected to further analysis in order to identify those with sufficient potential to facilitate the modernization drive specific to that operation or organization.

\section{Technology focus}

As mining companies begin to adopt innovative practices on a larger, more all-encompassing scale, they stand to gain significant value. When they leverage new and emerging technologies for increased synergy across the entire mining value chain, organizations can alter the fundamentals of the mining sector. For example, 3D visualization tools can assist companies with real-time tracking of their people, equipment, and changing environment at each mining site. New mineral processing technologies are emerging to reduce the safety hazards associated with gold extraction and to unlock previously uneconomic mineral deposits. Social media are assisting companies in facilitating electronic bookings at mine sites and enhance employee access to information. SMS messaging platforms help foster two-way communication with employees, solicit feedback, and improve workforce engagement. New production and logistics technologies also promise to reduce both the use of natural resources and harmful gas emissions. Vale's S11D project's mine and plant in Carajás, Brazil will, for example, consume $93 \%$ less water, use $77 \%$ less fuel, and produce $50 \%$ less greenhouse gas emissions than a comparable operation using conventional methods (Deloitte, 2015a).

Mining companies are already aware of the imperative to adopt technologies to accelerate automation and reduce fatalities, and have implemented various strategies to accomplish this. Investment in innovation for better technology application is an example. These have ranged from automation and enhanced drilling systems to data analytics and mobile technologies. Mining companies that have embraced innovation are improving mining intensity while reducing labour requirements, capital requirements, and energy intensity (Deloitte, 2016b). This is why leading companies continue to look at new technologies, such as nanomaterials, robotics, 3D printing, modular design, bioengineering, and alternative haulage, in an effort to further improve operational performance (Deloitte, 2014).

Similarly, in mineral exploration, technologies such as hyperspectral imaging and interferometric synthetic aperture radar hold potential value. These technologies are already in use to monitor ground subsidence, landslides, volcanoes, and active faults (TIA, 2012). Mining companies can also leverage techniques like simulation, technical modelling, and seismic technologies borrowed from the oil and gas industry, instead of engaging in traditional drilling. This can allow companies to identify mineral-rich deposits more cost effectively, while simultaneously helping the industry to maintain a sustainable discovery pipeline (Deloitte, 2015a).

In this information age, value creation is, however, dependent on more than just physical technologies. In order to improve long-term planning and forecasting, companies must also explore emerging information technologies. Examples include cloud computing, sensors, GPS systems, embedded logic, cyber-security, 'big data', 3D visualization, and simulation modelling (Deloitte, 2014).

Underground mines can also strive to implement realtime production management systems by using the latest technologies available. Some of these include low-cost offthe-shelf wi-fi networks and inexpensive wireless radiofrequency identification (RFID) tagging for vehicle and personnel location and tracking. Other non-physical technologies include software systems for mapping, modelling, estimation, design, scheduling, simulation, and mine production management reporting. These technologies have the potential to engender a fundamental change in the way mining operations are managed (Rivard, 2014).

Applying such technologies to real-time monitoring of production processes may enable faster decision-making in changing conditions (MacFarlane, 2014).

To combat rising energy costs, reduce unwanted emissions, and accelerate electrification, companies also need to investigate energy technologies. Some of these include advanced materials, smart grids, energy storage technologies, renewable energy conversion, superconductivity, nonexplosive rockbreaking, and high-energy lasers (Deloitte, 2014). In the energy space alone some operations have achieved $10 \%$ to $40 \%$ energy savings. This resulted from investment in renewable energy installations, deploying innovative energy technologies, and adopting more automated mine processes to optimize energy consumption (Deloitte, 2016b).

By integrating mining, energy, and information technology into mine and process design in an innovative way, it is possible to achieve radical breakthroughs in performance. When combined, these technologies can help companies reduce capital, labour, and energy intensity, while increasing mining intensity. Companies can also improve safety standards, reduce operating costs, optimize their energy mix, and enhance operational performance by combining these three technology groups (Deloitte, 2014).

It is therefore recommended that organizations consider technologies, such as those in the technology map, in an integrated manner in order to enhance synergy across the mining value chain for existing operations and across the broader mining cycle for the entire mining venture. In this way, companies may strive towards increased operational performance improvements. Such an approach often leads to improvements that far exceed the individual benefits of the application of a single technology in isolation. In this context, it should be borne in mind that the technology map does not provide insight into such potential gains, owing to the large number of possibilities resulting from technology and system integrations. The potential benefits of technologies were 


\section{A technology map to facilitate the process of mine modernization}

investigated individually, and these will be discussed. The resulting analysis serves as a guideline for companies or individuals that wish to extract information from the technology map. By analysing their potential value, technologies that should be considered for further research and development $(R \& D)$ can be identified and a tailor-made solution created for a specific organization, operation, environment, challenge, or problem area.

In this study, greater focus was placed on emerging technologies, such as those that have the greatest potential to be disruptive in nature or drive the largest economic impact across various industries, businesses, and countries. Recent technological advances outside of the primary scope were also investigated. These included technological innovations in mining as well as non-mining industries with potential to add value if applied (or modified for application) in the mining environment.

\section{Mapping the mining cycle}

In order to create a technology map that spans the entire mining cycle, a framework was constructed that is representative of the scope and specific needs of the study. The resulting mining cycle framework was a $7 \times 6$ matrix that covers the six mining phases, from exploration to after mine closure, and consisted of seven main value driving pillars. The pillars incorporate all aspects that impact mining and were classified as follows: mineral resource management; production; productivity and asset efficiency; profitability and cost control; supply chain; socio-economic factors; and, health, environment, safety, and legal. Figure 1 illustrates how these seven pillars form part of the general mining cycle and why they were chosen to represent the platform upon which the technology map was created. Figure 2 highlights a specific area within the mining cycle framework, namely the production pillar within the operations phase, and illustrates the various value drivers identified for this specific block in the framework.

It should be noted that no existing representations of a generic mining life-cycle were deemed sufficient in depth and/or description to be used as a basis for the technology map as per the needs of this study. For this reason, the illustrated framework was designed to address the needs and perspective of this study. As such, the classifications, definitions, groupings, level of detail, or other factors relating to the framework illustrated here may not be adequate for various other technology map designs. It is suggested that the system architecture for a technology map's platform be designed according to the requirements of each specific project or study.

After tabulating the value drivers for each corresponding pillar, the total matrix contained around 330 value drivers. All of the drivers represented potential opportunities for the investigated technologies (whether physical or digital, and for various systems and combinations of applications) to add value to a mining operation or organization as a whole. A high-level example would be increased 'digitization' of the development process, i.e. conversion to digital formats and the increased application of digital technologies to add value to the process. The constituent technologies to accomplish this may range from various digital to physical technologies. Applicable digital technologies may include 'big data', advanced analytics, machine learning, and various others that convert data into information and in turn into valueadding intelligence, enhancing decision-making or physical

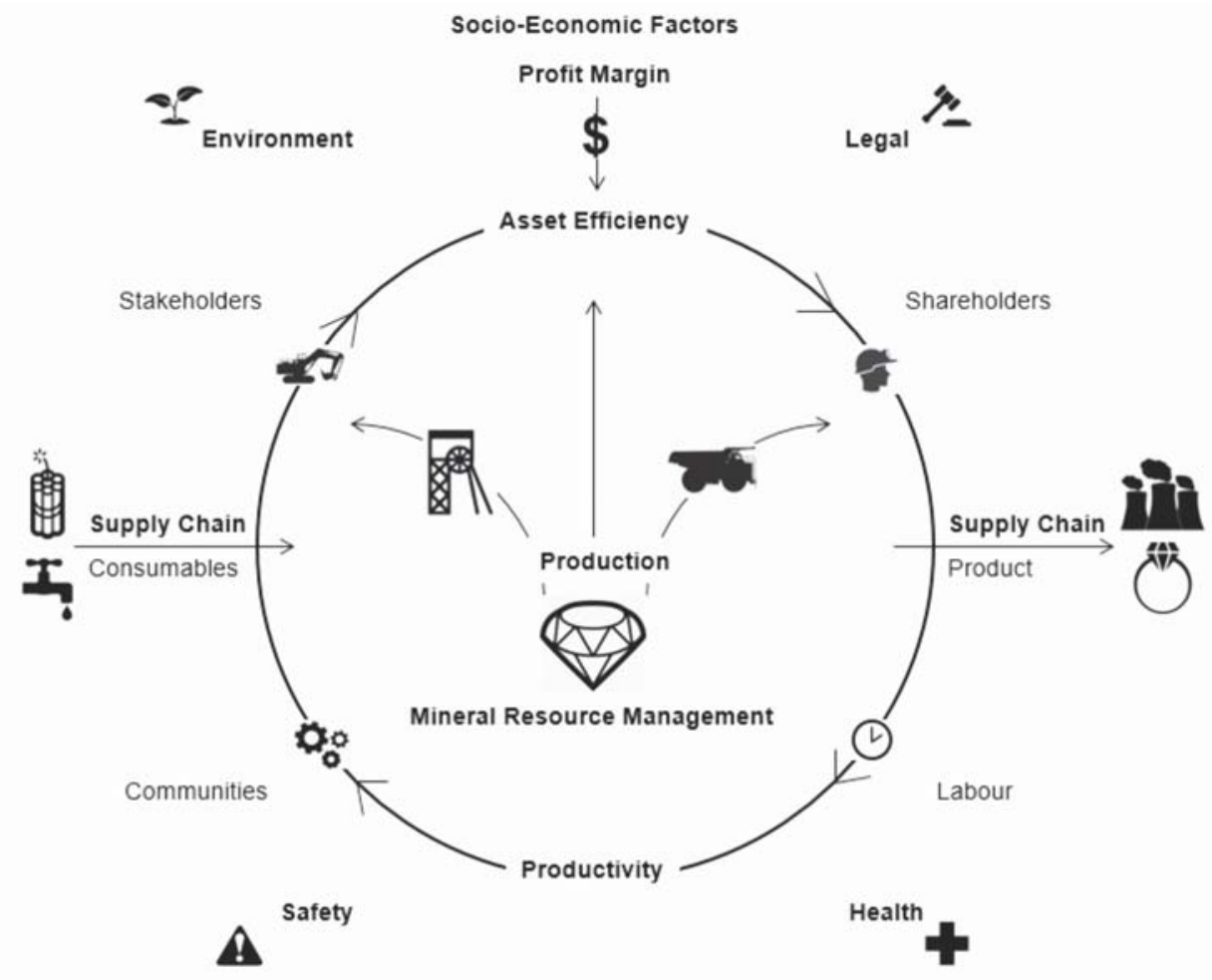

Figure 1-Visual representation for the mining cycle (Jacobs, 2016) 


\section{A technology map to facilitate the process of mine modernization}

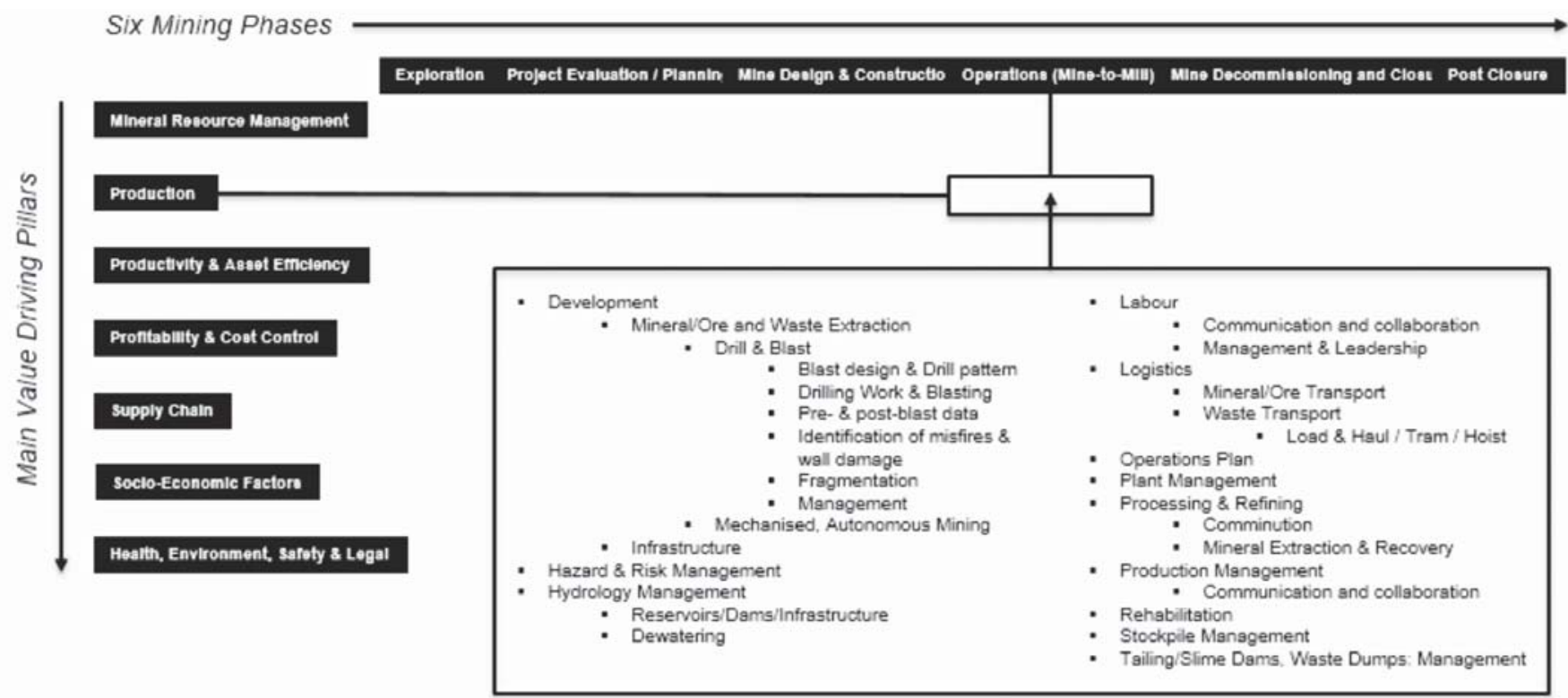

Figure 2-Mining cycle framework, indicating identified value drivers within a portion in the mining cycle (Jacobs, 2016)

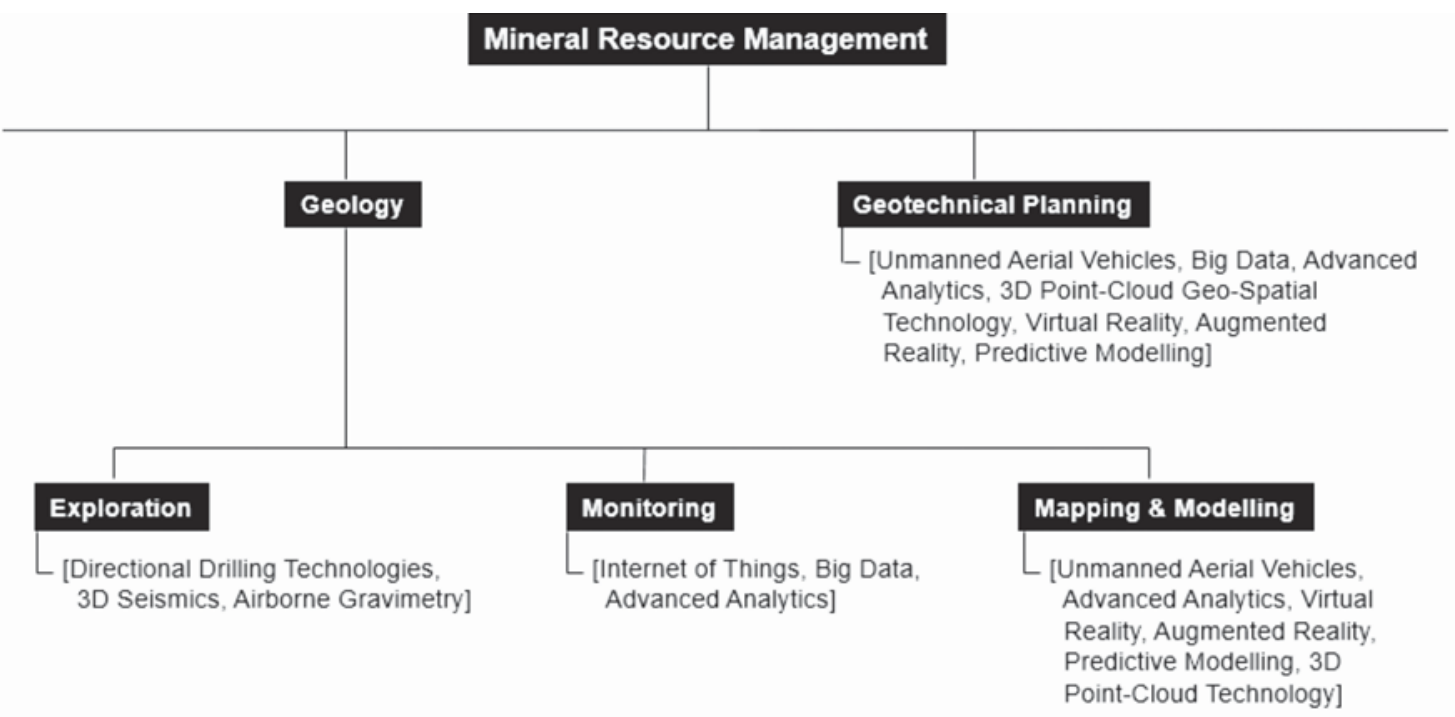

Figure 3-Technology map example 1 (Jacobs, 2016)

operation. The physical technology enablers may include the sensors for internet of things applications to extract the data, tracking technologies to monitor asset location and utilization, and robotics and ICT applications in rockbreaking or drill-and-blast-based mechanized equipment to enable remote operation.

\section{Creating a technology map}

To illustrate how the technology map was designed from the platform of the mining cycle and its constituent value drivers, consider the following examples of different sections taken from the technology map. Figure 3 displays a basic example from the operations phase under the mineral resource management pillar for the two chosen main value drivers: geology and geotechnical planning. Figure 4 is a more detailed example from the operations phase under the productivity pillar, with a specific focus on underground development as the main value driver. For this example, the chosen supporting value driver is mineral/ore and waste extraction, which in turn branches out to drill-and-blast and mechanized, autonomous mining.

Under each of these value drivers and/or constituent value drivers, the investigated technologies with potential to add value are shown in square brackets. These technologies, along with selected others from the technology map, will be discussed in relation to their potential areas of application within the mining cycle to provide context on how the technology map was designed. 


\section{A technology map to facilitate the process of mine modernization}

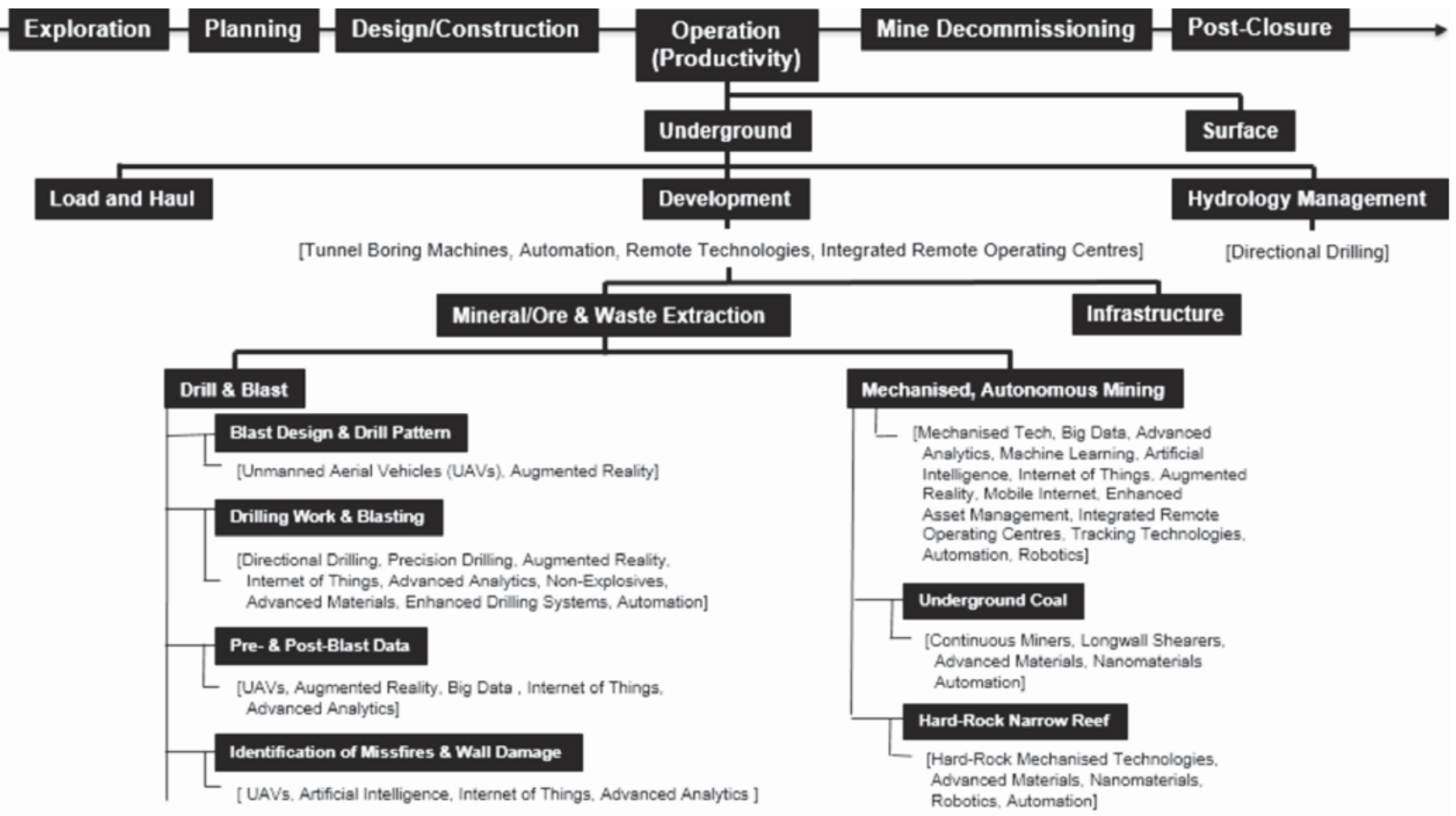

Figure 4-Technology map example 2 (Jacobs, 2016)

\section{Advanced analytics and big data}

Data is a foundational component of digital transformation. To realize the full potential that can be extracted from data, some businesses are treating data analysis as a strategic discipline and are investing in industrial-grade analytics (or advanced analytics). Advances in distributed data architecture, in-memory processing, machine learning, visualization, natural language processing, and cognitive analytics have unleashed powerful tools that can answer questions and identify valuable patterns and insights. To create value from big data through advanced analytics entails a process of information acquisition and curation, information delivery, turning information to insights, and insights to actions (Dupress, 2016a).

Analytics will become deeply, but invisibly, embedded everywhere. Organizations will face increased difficulty in managing the huge amounts of data (often termed 'big data') from the internet of things, social media, wearable devices, sensors, and other sources. Applying advanced analytics to an understanding of context could provide the preconditions for a world of smart machines. This foundation combines with advanced algorithms that allow systems to understand their environment, learn for themselves, and act autonomously (which further assists technologies such as artificial intelligence, machine learning, and deep learning). Prototype autonomous vehicles, advanced robots, virtual personal assistants, and smart advisors already exist and are evolving rapidly. This will ultimately usher in a new age of machine helpers, leading to a smart machine era that is likely to be the most disruptive in the history of information technology (Gartner, 2014).
As regards mining, global supply and demand factors lack the transparency that companies often require in order to make decisions before disaster ensues in their operations. Companies now need more flexibility than ever before, and should aim to hone their ability to scale production, labour, and other inputs and outputs up or down in response to shifting economic trends. Predictive analytics can help organizations in this regard by identifying events that may shift commodity market fundamentals (Deloitte, 2016c). Smart planning and coordination of activities are required to mitigate variability caused by external forces. Disciplined execution is needed to eliminate variability in operations. A step change in mining productivity will ensue through reducing and, where possible, eliminating the variability that has made mining unique (McKinsey, 2015a).

Mining companies continue to refine their safety programmes, but the statistics still remain unsatisfactory worldwide. Companies often turn to data analytics to pinpoint the industry risks, organizational behaviours, and internal cultures that are most likely to result in serious safety issues. As this technology becomes more intuitive and less costly, it is enabling companies to implement safety programmes focused on zero fatalities (rather than zero harm). Companies are able to better correlate the safety data they collect with other available data-sets (e.g. production data, employee rosters, maintenance schedules, weather forecasts, vehicle telemetry etc.). By correlating this data, companies can recognize safety incident patterns and employees that are particularly at risk. They are then in the position to adopt processes and procedures to minimize incidents and injuries (Deloitte, 2016c).

According to Deloitte (2014b), the use of analytics enables companies to: 


\section{A technology map to facilitate the process of mine modernization}

> Assess the costs of entire processes in order to reveal the underlying cost base and to identify exceptions and outliers

> Improve decision-making and asset performance through the measurement of both financial and nonfinancial indicators that affect overall profitability

> Merge data from a wide range of different sources to deliver on-demand reports. This then enables asset utilization and reliability to be improved. It would also minimize downtime, streamline mine planning, and optimize fleet resources

> Manage operational costs, for example by quantifying the mineral content of each shovel load to determine whether it is below cut-off grade.

As data analysis becomes increasingly more sophisticated, opportunities for greater efficiency arise. From a talent management perspective, companies can leverage vast sets of employee data to make more informed workforce planning decisions. The use of real-time information on the state of equipment can improve maintenance schedules and asset performance. The consolidation of various data inputs can streamline supply chains and enhance mine planning. Continuous monitoring of mineral asset portfolios can pinpoint commodity and cost movements that affect profitability. Using predictive project analytics, companies can vastly reduce cost overruns to improve capital project outcomes. By harnessing big data in real time, some companies are also optimizing mineral processing at localities around the globe from a single location. In time, operational excellence will likely hinge on an organization's ability to effectively interpret the massive stores of data it collects (Deloitte, 2015b).

Advanced analytics can also assist production supervisors to determine the optimal material blend and schedule production to optimize mine/plant throughput. It can likewise benefit strategic procurement programmes, in that category management, strategic sourcing, supplier integration, procurement centres of excellence (COEs), and transaction optimization can all work to reduce costs and waste in the supply procurement process (IBM, 2009).

While most information technologies prove to be not only greatly beneficial, but also critical, to all levels of an organization, the integration of various technologies is both the most difficult and the most lucrative aspect. Business leaders should pay special attention to how advanced analytics, huge volumes of data, the internet of things, artificial intelligence, machine learning, and automation all tie in together. The underlying component technologies will also play a critical role in the building of a global automation and real-time analytics system that not only responds to, but also predicts and adapts to, market and operational dynamics.

By keeping these applications in mind, it becomes clear how big data and advanced analytics may play a role in the identified value drivers from Figures 3 and 4. It may assist with geotechnical and geological planning, with the optimization of outputs such as scheduling, modelling, planning, and the monitoring of data from various sensors and devices (e.g. through a network of sensors such as the internet of things). Similarly, advanced analytics can assist in ore or waste extraction processes. In drill-and-blast practices, for example, advanced analytics may assist with drawing up blast patterns and setting up the correct angles and hole depths to be drilled based on data inputs on geological features. It may also assist with analysing blast data and making recommendations for load-and-haul activities in order to optimize fleet efficiency by taking into account the muckpile size, shape, and fragmentation. In mechanized and autonomous mining, advanced analytics can greatly assist by providing valuable insights from data obtained by sensors and other devices regarding the state of the machinery. Realtime data can be analysed to adjust machine performance, sequence, and system or fleet integration for optimal results.

\section{Advanced materials and nanomaterials}

Scientists have discovered ways to produce materials with enhanced attributes. Some of these include smart materials that are self-healing or self-cleaning, memory metals that can revert to their original shapes, piezoelectric ceramics and crystals that turn pressure into energy, and nanomaterials. Other properties include greater reactivity, unusual electrical properties, and greater strength. These properties can lead to the development of new medical devices and treatments, 'super-slick' coatings, and stronger composites (McKinsey, 2013). Provided that such materials can be produced in large quantities, they could replace composites and other materials in a wide range of applications. These nano-altered materials would be just as strong as their conventional counterparts, but with a fraction of the weight (Bourzac, 2015). Advanced nanomaterials such as graphene and carbon nanotubes could lead to new applications and technologies, such as highly efficient batteries and solar cells. Pharmaceutical companies are also progressing research to use nanoparticles for targeted drug delivery in medical treatments (McKinsey, 2013).

Advances in technology could allow further manipulation of material properties. Enhanced material characteristics could benefit equipment exposed to tough working conditions or abrasive environments, and potentially reduce consumption of materials used for rock cutting or breaking. When the strength-to-weight ratio of materials can be improved through technology, the impact and potential benefits will extend even further. Smaller, lighter, and stronger components may eventually allow deeper and safer mining by improving rock support. Ultra-low-profile equipment could then be designed smaller and stronger to mine difficult-to-navigate deposits, reduce waste mining, and therefore mine both more economically and be able to reach previously uneconomic deposits. Advances in this field could lead to major breakthroughs in electrical equipment and vehicles if energy storage can be improved and batteries reduced in size and weight.

\section{Advanced robotics}

Robots have undergone massive improvements over the last few decades, progressing from being expensive, bulky, and inflexible to becoming much more advanced. Currently, robots are gaining enhanced senses, dexterity, and intelligence. Many of these improvements stem from advances in machine vision, artificial intelligence, machineto-machine communication, sensors, and actuators (a component of machines that is responsible for moving or 


\section{A technology map to facilitate the process of mine modernization}

controlling a mechanism or system). Robots are now easier to program and interact with. They may also be more compact and adaptable, making it possible to deploy them alongside workers. As a result, advanced robotics could make it practical to substitute or complement human labour with robots in a wider range of manufacturing tasks and service jobs. This technology could enable new types of surgical robots, robotic prosthetics, and 'exoskeleton' supports that help people with limited mobility to function more normally and improve and extend lives (McKinsey, 2013).

The International Federation of Robotics estimated in 2013 that these devices will create as many as 2 million additional job opportunities between 2017 and 2020. A major factor in robotics-driven job growth is the fact that the combination of humans and machines can often produce better results than neither could accomplish on their own. In dire situations, an expert may always be required to take control (Dupress, 2015). Anthropomorphic robots (robots that mimic human characteristics), on the other hand, could take over numerous repetitive production functions or other tasks that traditionally required human traits (ESPAS, 2015). As robots become cheaper, more dexterous, and safer to use, they will continue to grow as a substitute for human activities in a wider range of fields (VanderMey, 2015).

The implementation of robotics in mining constitutes further progress towards technological advancement. An example of robotic machinery in mining is the ultra-lowprofile mining machines from CMTI Consulting in South Africa. These machines are currently in development and will be implemented at Sibanye Gold's Burnstone gold mine in Balfour, South Africa. The MT100, for example, has a sweeper and dozer attached and is battery-driven with a battery life of 7 hours. It is equipped with a drill rig and mechanical breaker for non-explosive mining, or a multi-drill rig that can drill four holes simultaneously for conventional blasting. It can also be equipped with a laser scanner while being operated from a gulley up to $100 \mathrm{~m}$ away. The machine is highly manoeuvrable, with track-based wheels, and can navigate difficult underground environments. Its multi-track concept, where four tracks are individually driven, further also allows the machine to swing around a centre point to enable it to negate vertical obstacles as high as $400 \mathrm{~mm}$ (Solomons, 2016).

Robotics in mining offer potential for improvements in safety, access to resources that were previously uneconomic to mine, and improvements in the larger mining cycle through the integration of different technologies. Some examples include automation, machine learning, integrated remote operating centres, the internet of things, and advanced analytics.

\section{Airborne gravimetry}

This system uses a gravimeter installed on an airborne platform such as a drone or small aircraft to measure variations in the Earth's gravitational field. In doing so, it can perform resource investigations from the air to assist with geological mapping (Förste, 2016). This can enhance geological exploration with electromagnetic surveys that provide greater coverage and depth (Holland, 2015).

\section{Artificial intelligence and machine learning}

Artificial intelligence (AI) refers to the field of study towards the creation of computers that are capable of intelligent behaviour and that could divulge answers by analysing data, as well as having the ability to learn autonomously by analysing data. Machine learning uses algorithms to analyse and learn from data and adapt the machine's behaviour accordingly. Machine learning is more specific in application, and also more accurate than $\mathrm{AI}$, since it is a more mature technology(Skylads, 2015). Both fields have undergone rapid advances, with major drives from technology leaders to increase the rate of development. Due to their massive potential in all aspects of information technology systems, it is vital for business leaders to remain aware of progress within the field.

\section{Augmented reality and virtual reality}

Virtual reality (VR) makes it possible for a user to be immersed within a computer-generated environment, which can represent either an actual place or an imaginary one. In contrast, augmented reality (AR) overlays contextual information on the immediate physical environment of the user. In this way, AR blends digital components (e.g. virtual elements such as text or 3D models) with real life. Both of these sensory (predominantly visual) technologies allow the deployment of technology in ways that were previously impossible. As such, they open up major possibilities for training, simulation, visualization, planning, and modelling (see Figure 2), communication, and collaboration (Dupress, 2016b). AR in particular holds great potential for human assistance; some examples include on-site task assistance and guidance, navigation, re-creations of incidents, maintenance and repair, emergency management, and search and rescue operations (Jacobs, 2015).

\section{Automation and automation of knowledge work}

Automation refers to the act of making a process, activity, task, system, or even decision autonomous. With the advances in autonomous equipment, robotics, artificial intelligence, and advanced analytics, many business improvements become possible through increased automation of operations. Rio Tinto has demonstrated that driverless trucks are already changing the cost equation in the mining industry in Western Australia. Further adoption of automated drills, automatic longwall shearers, autonomous trucks and trains, and remote operating technologies will increase the efficiency of many other operations (Deloitte, 2014c).

As the 'intelligence' of these machines grows, they will be able to perform more complex tasks, including maintenance and repair activities on equipment and hazardous processing activities. This will reduce labour costs and enhance productivity. It is likely that companies will ultimately operate fully autonomous mines, concentrating labour in centralized functional hubs rather than in remote regions (Deloitte, 2016c).

Automation is not limited to robotics and autonomous equipment in physical activities. It also includes the automation of knowledge work (VanderMey, 2015). Advances in artificial intelligence, machine learning, and natural user interfaces (e.g. voice recognition) are making it 


\section{A technology map to facilitate the process of mine modernization}

possible to automate many knowledge-worker tasks, many of which have long been regarded as impossible or impractical for machines to perform. For instance, some computers can answer 'unstructured' questions (those posed in ordinary language, instead of being precisely written as software queries), so employees without specialized training can obtain information on their own. This opens up possibilities for major changes in how knowledge work is organized and performed. Sophisticated analytics tools can then be used to enhance the talents of highly skilled employees. As more knowledge-worker tasks can be done by machines or computers, it is also possible that some types of jobs could eventually become fully automated (McKinsey, 2013). A few examples include administering procurement, processing payrolls, calculating materials resource needs, generating invoices, and tracking flows of material (McKinsey, 2016).

\section{Directional drilling}

Directional drilling is a mature technology, with widespread use in the oil and gas, utilities, and infrastructure industries (Dowling and Rhys-Evans, 2015). The technology, while already applied in mining (e.g. for in-seam exploration in coal mining), holds potential for greater adoption in various areas. One such application, for example, is dewatering well placement. Directional drilling allows the placement of permanent, high-performance dewatering wells in optimum orientations beneath an open pit, using directional drilling technology to direct the large-diameter drilling heads from outside the pit to intersect chosen geological structures. Pilot directional dewatering wells in hard-rock mining environments in the USA and Mexico have demonstrated significant benefits, such as better control of groundwater inflow, improved in-pit safety, and fewer disruptions to operations compared to conventional dewatering. Directional dewatering wells produce up to two orders of magnitude more groundwater than in-pit vertical wells (Rowland et al., 2016).

\section{Energy technologies}

\section{Technologies that increase energy efficiency}

Technologies identified by McKinsey (2015b), for this purpose include energy-management systems, advanced analytics, and smart grids.

\section{Renewables}

Renewable energy sources, such as solar, wind, hydroelectric, and ocean waves, promise an endless source of power. Solar cell technology, in particular, is progressing at a rapid rate with drastic reductions in costs. (McKinsey, 2013). Many companies already employ solar, wind, hydro, and biomass power generation technologies. These are often supplemented by variable-speed backup generators capable of maximizing fuel efficiency, which is a solution that also works for companies that run power off the grid (Deloitte, 2016c). With the rate of reduction in costs relating to renewables, it makes sense for energy-intensive enterprises to critically evaluate these technologies (Davidse, 2016).

\section{Technologies that reduce energy consumption}

Technologies identified by McKinsey (2015b), for this purpose include automated mine ventilation control and air- reconditioning, high-pressure grinding rolls, in-pit crushingconveyance and high-angle conveyance systems, low-loss conveyor belts, stirred-media mills, coarse flotation, fuel-cellpowered mine vehicles; and electro- and hydropowered drilling.

\section{Genomics and precision agriculture}

Genomics combines advances in the science of sequencing and modifying genetic material with the latest big data analytics capabilities (McKinsey, 2013). In short, genomics combines biology, genetics, and computer science (GenomeCanada, 2016). In mining, genomics solutions have already been used to bioremediate polluted soils, improve mine drainage, and mitigate threats to biological diversity through biomonitoring (Deloitte, 2016c). By understanding the way microbes function, bioleaching can be enhanced and applied more efficiently. This can improve metal recoveries by as much as 50\%. Overall, this technology can help improve productivity, cut costs, and improve sustainability in the mining industry (GenomeCanada, 2016). The technology can also be used in agriculture, which may assist mining companies in their corporate social responsibility activities, or in motivating the application for a mining licence during the exploration and mine design phases. This argument also applies for precision agriculture, which is a new, site-specific farm management system that utilizes technologies and agronomic principles to optimize farm yields by collecting data on the spatial and temporal variability of the various agricultural components (such as soil, climate, seed, fertilizers, water, pests, animals, and diseases), thus enabling micromanagement of the relevant factors (Frost and Sullivan, 2016).

\section{Internet of things}

The internet of things (IoT) concerns embedded sensors and actuators in machines and other physical objects that connect them to the internet. This allows the flow of products and assets to be monitored while taking other data, such as the weather, into account. The data provided through the IoT enables assets to be better managed, performance to be optimized, and new business models may be created. With remote monitoring, the IoT has potential to improve various aspects and systems ranging from the health of patients with chronic illnesses to improved synergy between fleet equipment (McKinsey, 2013). Sensors to collect this data, for processing and control purposes, will be able to obtain information on the health of machinery, the structural integrity of bridges, and even seemingly redundant information such as temperatures in the environments surrounding different assets (VanderMey, 2015).

\section{Tracking technologies}

Tracking technologies, such as Radio-Frequency Identification (RFID), global positioning systems, Wi-Fi, unmanned aerial vehicles equipped with cameras and sensors, and thermal imaging may greatly assist various areas within the mining cycle. By using such technologies, companies can deploy sophisticated and automated identification and security management programs that can systematically track employees' access rights, location, duration, training, safety certification, permissions, 


\section{A technology map to facilitate the process of mine modernization}

compliance, and site security from a central location. This information can then be integrated and made available to those who need it, including security and human resources personnel. Tracking of employees can also greatly assist during search-and-rescue operations, as well as enhance the effects of proximity detection and collision avoidance systems. These aspects can be integrated into a comprehensive location awareness and safety programme, with a real-time visualization engine that provides a rich graphical view of employee locations and associated metrics (IBM, 2009).

\section{D printing (additive manufacturing)}

Additive manufacturing is the technique employed by 3D printers that allows the creation of an object by adding ultrathin layers of material on each other (LaMonica, 2013). The performance of additive manufacturing machinery is improving, the range of materials is expanding, and prices (for both printers and materials) are decreasing. These factors allow rapid adoption and open up more manufacturing uses for the technology. With 3D printing, a 3D design file can be taken directly to a finished part or product, potentially skipping many traditional manufacturing steps. The ability to achieve on-demand production has massive impacts on supply chains and the stocking of spare parts, both of which involve great costs. 3D printing can also reduce the amount of material wasted in manufacturing and create objects that are difficult, or even impossible, to produce with traditional techniques (McKinsey, 2013).

As this technology matures, the entire equipment supply chain is set to shift, driving OEMs to favour modular designs. For instance, European Truck Factory is bringing this concept to fruition with the design of modular components for use in a full array of mining trucks. As more equipment becomes modular, mining operations can also begin to rely more on new forms of heavy lifting transport, such as hybrid air vehicles, which combine blimp, helicopter, and fixed-wing aircraft designs in new types of flying machine (Els, 2016) that are capable of moving modular equipment to remote sites. This will enable operations to construct processing units in low-cost factories and transport them to where they will be used (Deloitte, 2016c). Hybrid airship technology itself is another new field with great potential for mining. These airships will be capable of carrying large loads, be easy to manoeuvre, fly at low speeds, and the transportation costs will be comparable to that of truck transport on icy roads (Shalal, 2014).

\section{Conclusion}

In the context of this paper, the sheer size of the created technology map cannot be represented in full. Due to this, a few selected examples were presented of technologies embedded in the technology map, with the potential to add value to various areas within the mining cycle. By applying some, or a combination, of the technologies in innovative ways, operations may stand to gain significant business value. This value was analysed in terms of the potential of a technology to facilitate the process of mine modernization, based on its ability to increase production, productivity, or efficiency, improve safety, or reduce the risk of human error. It should be noted that all the technologies were investigated from a holistic perspective and they do not provide 'plug-andplay' solutions for any mining operation. As such, the technology map serves to identify technologies suitable for further research and development towards creating a tailormade solution or application specific to the needs of the user.

\section{Suggestions for further work}

It is recommended that the framework for the mining cycle should be expanded to include all subsequent functions, activities, systems, and other constituents for each of the main value drivers. As such, a blueprint could be created that is representative of all aspects related to mining, for all mining methods, geological characteristics, geographical factors, commodity types, and other variables. Such a blueprint for mining should be made publicly available to assist further research and development, academia, service providers, consulting/advisory firms, and other organizations, as it would clarify the often 'fuzzy' context of the mining industry. The mining blueprint will then provide a rigid structure that is fully representative of the mining industry and its cycles or phases along with greater detail on all the constituent value drivers that make up a mining enterprise. The blueprint should then be ported to a digital platform that can be used for various purposes. One example is the overlaying of potentially applicable technologies for the various components within the mining cycle, to create a mining technology map, as was done in this study.

In the same way in which the technology map has been created from such an overlay, so too can other applications be found that could build on the foundation of the mining cycle. Other examples may be the benchmarking of various figures, or leading practices applicable to different mining activities. The overlaying of such information on a well-structured foundation will assist both mining and non-mining experts in building the understanding required for a specific task or project. More often than not, non-mining professionals lack exposure to the mining environment and as such have difficulty in visualizing the various aspects of mining. By combining a digital mining cycle platform with visual technologies, this understanding could be enhanced in order to increase the efficiency and accuracy with which such professionals perform their work.

Another recommendation is to incorporate a wider range of technologies in the technology map, i.e. existing technologies that are currently in use in industry as well as all new and emerging technologies with potential to add value or have an impact. Furthermore, the level of analysis and number of factors analysed should be increased in order to gain deeper understanding of each technology's feasibility and implementability in a mining system context. The current technology map drew its information from a desktop-level analysis of the technologies, which assessed potential to add value. It would, however, be of great value to include more detailed analysis on system implications, technology maturity (or technology readiness level), and risk of adoption for each technology (both for a system application and for a component), as well as on-the-ground assessment of 


\section{A technology map to facilitate the process of mine modernization}

suitability for mining environments where possible. Such a tool would assist companies with technology adoption timeline planning (technology roadmapping).

The proposed mining technology map should then be digitized in order to effectively create a search engine regarding technologies that are applicable to mining. It is recommended that such a digital mining technology map be made publicly available in order to reduce the resources that various organizations, institutions, and individuals spend on doing similar research. By collectively pooling $R \& D$ on general (non-proprietary) technologies instead of working in silos, the industry stands to gain value and reduce waste on $R \& D$.

Lastly, it is suggested that a technology intelligence (TI) system framework should be created specifically for such a mining technology map. The TI system should aim to scientifically structure the gathering of intelligence along with appropriate knowledge and information management in the technology map. It should also provide a dissemination process for the technology intelligence into value-adding decision-making. The latter would serve as a decisionmaking tool to provide guidance in identifying applicable technologies based on inputs of variables, factors, or other criteria as provided by the user of the technology map. This would further assist with the refinement process when using the technology map. As such, it would reduce the applicable number of technologies, and potentially their desired designs and method of application, to a level applicable to the needs of the user. This decision-making tool could then be developed to include the ability to align business strategies and operational risk management strategies with the technology map. The user would then have a complete tool that is able to take inputs based on organizational and operational parameters and identify technological solutions that have the potential to add value to a component of the mining cycle. This should be followed by a well-structured and proven refinement (research and development) process.

\section{Acknowledgements}

The following persons are gratefully acknowledged for their inputs in shaping the platform for the mining cycle:

- $\quad$ Andre Liebenberg

- Carel Anthonissen

- $\quad$ Carel de Jager

- $\quad$ Eugene Preis

- Jan Britz

- Jannie Maritz

- Johan Hanekom

- Marinus du Plessis

- $\quad$ Pierre Bredell

- Tinus Pretorius

- Wolter de Graaf

\section{References}

BouRZAc, K. 2015. Nano-architecture: A Caltech scientist creates tiny lattices with enormous potential. https://go.ted.com/CyGv [Accessed 5 July 2016].

Bryant, P. 2011. The Case for Innovation in the Mining Industry. Clareo Partners, Chicago.
COMSA, 2016. Modernisation: towards the mine of tomorrow. Chamber of Mines of South Africa, Johannesburg.

DAvidSE, A. 2016. Personal correspondence. Mining Innovation Leader, Deloitte Canada.

DeloitTe. 2014. The future of mining in South Africa - Innovation imperative. Deloitte $\&$ Touche, Johannesburg.

DeLorTte. 2014b. Deloitte Global Services Limited, London - Mining spotlight on: Sliding productivity and spiralling costs. http://bionanouni.wdfiles.com/local--files/teaching-im010-horario2014i/Deloitte_14-Mining-Spotlight-On_Sliding-Productivity-andSpiraling-Costs.pdf [Accessed 29 January 2016].

DeLorTte. 2014c. Mining spotlight on: Remaking mining.

http://www2.deloitte.com/content/dam/Deloitte/global/Documents/Energy -and-Resources/gx-er-remaking-mining.pdf [Accessed 26 January 2016].

DeLorTte. 2015a. Tracking the trends 2015: The top 10 issues mining companies will face this year.

https://www2.deloitte.com/content/dam/Deloitte/fpc/Documents/secteurs/ energie-et-ressources/deloitte_etude-tracking-the-trends-2015-en.pdf [Accessed 10 February 2016].

DeLoITTE. 2015b. Tracking the trends 2015: The top 10 issues mining companies will face this year.

https://www2.deloitte.com/content/dam/Deloitte/fpc/Documents/secteurs/ energie-et-ressources/deloitte_etude-tracking-the-trends-2015-en.pdf. [Accessed 10 February 2016].

DelorTte. 2016. Innovation State of Play I Mining I Deloitte Southern Africa. Available at: http://www2.deloitte.com/za/en/pages/energy-andresources/articles/innovation_in_mining.html [Accessed 4 May 2016].

DeloitTe. 2016b. Tracking the trends 2016: The top 10 issues mining companies will face in the coming year. Deloitte Touche Tohmatsu Limited. Annual Report. United Kingdom.

DeLoitTE. 2016c. Tracking the trends 2016: The top 10 issues mining companies will face in the coming year. Deloitte Touche Tohmatsu Limited. Annual Report. United Kingdom.

Dowling, J. and RHys-Evans, G. 2015. Oilfield directional well placement technology used for mine dewatering. Mining Magazine, May 2015. p. 28.

DuPRESS. 2015. Exponentials. http://dupress.com/articles/tech-trends-2015exponential-technologies/ [Accessed 29 July 2016].

DuPRESS. 2016a. Industrialized analytics - Data is the new oil. Where are the refineries? http://dupress.com/articles/data-assets-andanalytics/?id=gx:2el:3dc:dup3040:awa:cons:tt16 [Accessed 28 July 2015].

DuPRESS. 2016b. Augmented and virtual reality go to work. http://dupress.com/articles/augmented-and-virtualreality/?id=gx:2el:3dc:dup3036:awa:cons:tt16 [Accessed 26 July 2016]. 


\section{A technology map to facilitate the process of mine modernization}

ELs, F. 2016. Breakthrough aircraft to transform remote mining. http://www.mining.com/breakthrough-aircraft-to-transform-miningeconomics/ [Accessed 4 August 2016].

ESPAS. 2015. European Strategy and Policy Analysis System (ESPAS): Global Trends to 2030: Can the EU meet the challenges ahead? http://europa.eu/espas/pdf/espas-report-2015.pdf [Accessed 3 April 2016]

FöRSTE, C. 2016. Terrestrial and airborne gravimetry. http://www.gfzpotsdam.de/en/section/global-geomonitoring-and-gravityfield/topics/terrestrial-and-airborne-gravimetry/ [Accessed 25 October 2016]

Frost \& SulLivan. 2016. Top 50 emerging technologies: growth opportunities of strategic imperative - Multi-billion dollar technologies ready to propel industries and transform our world. http://ww2.frost.com/news/pressreleases/frost-sullivan-reveals-50-emerging-technologies-set-transformindustries-and-propel-growth-opportunities-across-globe [Accessed 19 April 2016]

GARTNER. 2014. Gartner identifies the top 10 strategic technology trends for 2015. http://www.gartner.com/newsroom/id/2867917 [Accessed 31 May 2016]

GenomeCAnAdA. 2016. Mining I Genome Canada. http://www.genomecanada.ca/en/why-genomics/genomics-sector/mining [Accessed 28 April 2016]

GRIFFITH, C. 2015. Modernisation - a vital step in building a sustainable mining industry in South Africa. Mining Indaba 2015 (Speech).

Holland, N. 2015. Gold Fields: the gold mining company of the future. https://www.goldfields.co.za/pdf/presentations/2015/gold_fields_mine_of _the_future_28102015.pdf [Accessed 18 May 2016].

IBM. 2009. Envisioning the future of mining https://www.ibm.com/smarterplanet/global/files/ca_en_us_oil_smarter_ natural_resources_future_of_mining.pdf [Accessed 17 February 2016].

INDEXMUNDI. 2016. Commodity metals price index monthly price - index number. http://www.indexmundi.com/commodities/?commodity=metalsprice-index\&months=60 [Accessed 18 July 2016].

JACOBS, J. 2015. A critical investigation into the potential of augmented reality applications in the mining industry. B.Eng (Hons) (Mining Engineering) dissertation, Department of Mining Engineering, University of Pretoria, South Africa.

JACOBS, J. 2016. Creating a technology map to facilitate the process of modernisation throughout the mining cycle. M.Eng (Mining Engineering) thesis, Department of Mining Engineering, University of Pretoria, South Africa.

LAMonicA, M. 2013. Additive manufacturing: GE, the world's largest manufacturer, is on the verge of using 3-D printing to make jet parts. https://www.technologyreview.com/s/513716/additive-manufacturing/ [Accessed 26 February 2016].
MacFarLane, M. 2014. Dassault Systemes GEOVIA: natural resources - special report on mining innovation.

http://www.geovia.com/sites/default/files/campaigns/GEOVIA_SpecialRep ortMiningInnovation.pdf [Accessed 4 March 2016].

McKinsEy. 2013. Disruptive technologies: Advances that will transform life, business, and the global economy.

https://www.sommetinter.coop/sites/default/files/etude/files/report_mckin sey_technology_0.pdf [Accessed 28 January 2016].

McKINSEY. 2015a. How digital innovation can improve mining productivity. http://www.mckinsey.com/industries/metals-and-mining/ourinsights/how-digital-innovation-can-improve-mining-productivity [Accessed 11 March 2016].

McKinsey. 2015b. Greening the future: New technologies that could transform how industry uses energy. Mckinsey \& Company. Global Editorial Services.

McKinSEY. 2016. Where machines could replace humans-and where they can't (yet). http://www.mckinsey.com/business-functions/businesstechnology/our-insights/where-machines-could-replace-humans-andwhere-they-cant-yet [Accessed 25 July 2016].

RIVARD, L. 2014. Dassault Systemes GEOVIA: Special report on mining innovation: mine owners focus on technology to control costs. http://www.geovia.com/sites/default/files/campaigns/GEOVIA_SpecialRep ortMiningInnovation.pdf [Accessed 4 March 2016].

Rowland, A., Bester, M., Boland, M., Cintolesi, C., and Dlowling, J. 2016. Adapting oil and gas drilling techniques for the mining industry with dewatering well placement technology. Proceedings of the New Technology and Innovation in the Minerals Industry Colloquium, Emperors Palace, Gauteng, South Africa. Southern African Institute of Mining and Metallurgy, Johannesburg.

SHALAL, A. 2014. Lockheed sees buyer for hybrid cargo airships in 2015. http://www.hybridairvehicles.com/news-and-media/lockheed-sees-buyerfor-hybridcargo-airship-in-2015 [Accessed 29 April 2016].

SкYLADS. 2015. What is the difference between machine learning and artificial intelligence? http://www.skylads.com/rtb-blog/what-is-the-differencebetween-machine-learning-and-artificial-intelligence [Accessed 28 July 2016].

Solomons, I. 2016. New ultralow-profile mining machine operated successfully for 500 hours at SA mines.

http://www.engineeringnews.co.za/article/locally-manufactured-miningmachine-trialled-successfully-2016-02-12 [Accessed 10 July 2016].

TIA. 2012. The mining sector innovation strategies implementation plan. http://www.tia.org.za/CMS/uploaded_docs/TIA\%20Mining\%20and\%20M nerals\%20Innovation\%20Strategies\%20Implementation\%20Plan\%20(201 2\%20-\%202016).pdf [Accessed 4 February 2016].

VanderMey, A. 2015. The 12 disruptive tech trends you need to know. http://fortune.com/2015/07/22/mckinsey-disruptive/ [Accessed 19 February 2016]. 